\title{
Efficiency of Sweet Potato (Ipomoea batatas L.) Genotypes in Retention of Processing Qualities under Ambient Conditions
}

\author{
Prathiksha* and K. Ramachandra Naik \\ Department of PHT, UHS Bagalkot, University of Horticultural Sciences, Bagalkot, \\ Karnataka, India \\ *Corresponding author
}

\section{A B S T R A C T}

\section{Keywords}

Sweet potato,

Genotypes,

Ambient conditions

Article Info

Accepted:

20 May 2019

Available Online:

10 June 2019
Sweet potato (Ipomoea batatas L.) is the sixth most important crop grown worldwide after wheat, rice, maize, potato and cassava and is considered as staple food in many developing countries. The largest quantity of sweet potato production is noticed in Asia and the Pacific Islands (93\% of global production). However, sweet potatoes face the problem of weevils, shrinkage and loss of nutrients in storage. Therefore, present research on shelf-life and physicochemical parameters of 12 different sweet potato genotypes were studied in order to determine the varieties for better storage. Among those, the genotype $\mathrm{BSP}_{1}$ was found to be good and exhibited superior qualities like high dry matter $(61.7 \%)$, low values for TSS (4.4 ${ }^{\circ}$ Brix), reducing and non reducing sugars $(0.67$ and $0.21 \%)$, starch $(0.60 \%)$ and physiological loss in weight $(13.5 \%)$ throughout the storage period. The genotypes Sree Bhadra and $\mathrm{BSP}_{23}$ were the next best genotypes to maintain all the above mentioned characters.

\section{Introduction}

The sweet potato (Ipomoea batatas L.) is a semi-perishable commodity. Appropriate and efficient post harvest technology and marketing are critical to the entire productionconsumption system of sweet potato because of its bulkiness and perishability. The purpose of storage is to maintain tubers in marketable condition and to provide a uniform flow of tubers to market and processing plants throughout the year. It must be realized that storage losses cannot be avoided even by optimal storage (Maldegem, 1999). Storage losses are mainly caused by the processes like respiration, weevil incidence, sprouting, evaporation of water from the tubers, spread of diseases, changes in the chemical composition and physical properties of the tuber and damage by extreme temperatures.

The main objective of present study was to test efficiency of different sweet potato genotypes for retention of processing qualities under ambient storage conditions.

\section{Materials and Methods}

The present investigation was carried out in northern dry zone (Zone-3) of Karnataka state at $16^{\circ} 15^{\prime}$ north latitude, $74^{\circ} 45^{\prime}$ east longitudes and at an altitude of $612.05 \mathrm{~m}$ 
above the mean sea level, in the laboratory Rashtriya Krishi Vikas Yojana (RKVY) research unit of the Department of Postharvest Technology, Kittur Rani Channamma College of Horticulture (University of Horticultural Sciences, Bagalkot), Arabhavi, Gokak Taluk and Belgaum district of Karnataka state during the period from 2016-17.

\section{Selection and preparation of sweet potatoes for experiment}

Representative even sized fresh sweet potatoes tuber of different varieties were procured from the research field of AICRP Tuber crops, operating at Regional Horticulture Research and Extension Centre, Dharwad of Karnataka state.

Tubers were well matured and free from damage of pest and disease infestation. Procured sweet potatoes were washed under running tap water to remove adhered soil; damaged and infected tubers were discarded and good tubers were dried under shade.

\section{Total soluble salts $\left({ }^{\circ}\right.$ Brix $)$}

The total soluble solids (TSS) of the sweet potato genotypes were estimated using the hand held refractometer on the different days of observation. A small amount of the flesh of tuber was crushed using mortar-pestle and its juice was obtained by filtering it using multiple layers of muslin cloth. The obtained clear juice was applied in drops on the prism of the calibrated refractometer and the values were read.

\section{Beta-carotene content (mg/100g)}

Beta-carotene present in sweet potato tubers was estimated by using petroleum ether method.

\section{Dry matter content (\%)}

Dry matter content of sweet potato tubers was determined by drying the finely sliced piece of tuber in microwave oven (Onida Power Barbecue-28, MIRC Electronics ltd., Mumbai) at 40 and 60 power intensity until the constant weight was achieved. The dry weight was calculated using the following formula.

Dry matter content $(\%)=\frac{\mathrm{W}_{2}}{\mathrm{~W}_{1}} 100$

Where,

$\mathrm{W}_{1}=$ Fresh weight of the tubers

$\mathrm{W}_{2}=$ Dry weight of the tubers

\section{Reducing and Non-reducing sugars (\%)}

The reducing and non reducing sugars present in sweet potato tuber genotypes were estimated using 3, 5-Dinitro Salicylic Acid (DNSA) method (Miller, 1972).

\section{Starch (\%)}

Starch content in sweet potato tubers was estimated by anthrone reagent method. The sample was treated with 80 per cent alcohol to remove sugars and then starch was extracted with perchloric acid (52\%).

In hot acidic medium starch was hydrolyzed to glucose and dehydrated to hydroxylmethyl furfural, this compound forms a green colored product with anthrone (Bates et al., 1943).

\section{Ascorbic acid content (mg/100g)}

Ascorbic acid content of sweet potato tubers was estimated by using the method given by AOAC (1990), which was based on the reduction of 2,6-dichlorophenol indophenols (2,6-DCPIP) by ascorbate. 


\section{Total titratable acidity (\%)}

The total titratable acidity of sweet potato was estimated by titrating the sample against strong base i.e. $\mathrm{NaOH}$.

\section{Physiological loss in weight (\%)}

The physiological loss in weight (PLW) was estimated at an interval of 15 days during storage. Initial tuber weight was recorded at the beginning of the storage period. The tubers were weighed and the weight was termed as final weight on the particular date of observation. The following formula was employed to calculate the PLW for each date of observation.

Physiological loss in weight $(\%)=\quad \underline{\text { Initial weight }- \text { Final weight }} X 100$

Initial weight

\section{Results and Discussion}

The observations on different parameters of sweet potatoes stored in ambient condition are discussed below.

\section{Total soluble solids $\left({ }^{\circ} \mathrm{Brix}\right)$}

In present investigation, the total sugars of sweet potato tubers increased continuously up to the end of the experiment (Table 1). Accumulation of total sugars could be attributed to the dormancy release and onset of sprouting as thereafter the cultivars showed sprouting, which continued to increase up to the end of experiment (Abdullah and Safraiy, 2015).

Initially the maximum value for TSS (7. ${ }^{\circ}$ Brix) was recorded genotype $\mathrm{BSP}_{23}$. On $15 \mathrm{DAS}$, the genotype $\mathrm{BSP}_{3}$ had maximum value $\left(7.7^{\circ}\right.$ Brix) for TSS and on $30 \mathrm{DAS}$, maximum amount for TSS $\left(7.8^{\circ} \mathrm{Brix}\right)$ was recorded in the genotype $\mathrm{BSP}_{2}$. The change in sugar content during storage consequently increased the ratio of reducing sugars to nonreducing sugar. Observations made in this experiment are similar to the findings of Kumar et al., (2002) and Huang et al., (2014).

\section{Beta-carotene $(\mathrm{mg} / \mathbf{1 0 0 g})$}

Beta-carotene is sensitive to heat and oxygen as opined by Emmanuel et al., (2010).
Oxidation of carotenoids results in the loss of beta-carotene in the fruits and vegetables as reported by Shekhar et al., (2015). In the present investigation, the highest betacarotene was recorded in the orange fleshed genotype $\mathrm{BSP}_{23}$ on initial day, 15 DAS and 30 DAS $(13.64,13.00$ and $12.46 \mathrm{mg} / 100 \mathrm{~g}$ respectively).

Sree Bhadra was found to be next to $\mathrm{BSP}_{23}$ by maintaining second highest content of betacarotene. This variation occurred due to the difference in flesh colors which is a genotype dependent factor (Blessington et al., 2010, Desai et al., 2013).

\section{Dry matter content (\%)}

The dry matter in the tubers increases during storage. However the amount of increase varies between genotypes (Ellong et al., 2014). In the present investigation, the highest dry matter was observed in the genotype $\mathrm{BSP}_{23}$ on all the days of storage i.e. initially, 15 and 30 DAS (44.0, 46.2 and $48.1 \%$ respectively). These results are in conformity with study undertaken by Serge and Tom (1996).

\section{Reducing and non-reducing sugars (\%)}

In an investigation by Kumar et al., (2002) opined that the reducing sugars is a variety dependent factor. In the present study, the 
genotype $\mathrm{BSP}_{23}$ exhibited the maximum amount of reducing sugars $(1.44,1.37,1.19 \%$ respectively) on first, $15^{\text {th }}$ and $30^{\text {th }}$ day. The minimum value for reducing sugars $(0.35 \%)$ was recorded in $\mathrm{BSP}_{1}$ at the end of experiment. It also recorded the maximum content of non-reducing sugars (0.42 and $0.59 \%$ ) on 15 and 30 DAS.

Decrease in reducing sugars and increase in non-reducing sugars was due to utilization of reducing sugars for the metabolic processes in the tubers during storage and accumulation of non-reducing sugars due to sprouting (Ingabire and Hilda, 2011).

Pressey and Shaw (1996) also observed a decline in reducing sugars during storage at higher temperature with sweet potato. Similar results were cited by and Agbemafle et al., (2014) in potato.

\section{Starch (\%)}

Amount of starch in different varieties is a character which varies with genotype and different chemical constituents in the tubers as quoted by Zhang et al., (2002). In the present investigation, the maximum amount of starch was recorded in $\mathrm{BSP}_{23}(1.30 \%)$ initially and same genotype had maximum of 1.23 and 1.07 per cent starch respectively after 15 and 30 days of storage. Starch content of sweet potato tubers, which is indeed a varietal trait, slightly decreased during storage (Table 2). The decline in starch content was correlated with $\alpha$-amylase activity in storage. There was a stronger positive and significant correlation between starch and reducing sugar content. The reduction in starch was due to the catabolic reactions in storage leading to conversion of complex starch molecules into simpler sugars. Similar reports have also been made by Khayatnezhad et al., (2011).

Table.1 Performance of sweet potato genotypes in retaining TSS ( ${ }^{\circ}$ Brix), Beta-carotene $(\mathrm{mg} / 100 \mathrm{~g})$ and Dry matter (\%) during ambient storage

\begin{tabular}{|c|c|c|c|c|c|c|c|c|c|}
\hline \multirow[t]{3}{*}{ Genotypes } & \multicolumn{3}{|c|}{ Total soluble solids ( ${ }^{\circ}$ Brix) } & \multicolumn{3}{|c|}{ Beta-carotene (mg/100g) } & \multicolumn{3}{|c|}{ Dry matter content $(\%)$} \\
\hline & \multicolumn{9}{|c|}{ DAS } \\
\hline & $\mathbf{0}$ & 15 & 30 & $\mathbf{0}$ & 15 & 30 & $\mathbf{0}$ & 15 & 30 \\
\hline $\mathbf{B S P}_{1}$ & 4.4 & 6.1 & 6.3 & 1.24 & 0.93 & 0.74 & 38.3 & 41.5 & 43.3 \\
\hline $\mathbf{B S P}_{2}$ & 6.1 & 7.7 & 7.8 & 1.65 & 1.34 & 1.19 & 33.4 & 38.1 & 41.7 \\
\hline $\mathbf{B S P}_{3}$ & 5.2 & 5.8 & 5.5 & 0.79 & 0.68 & 0.63 & 31.6 & 33.6 & 39.5 \\
\hline $\mathbf{B S P}_{4}$ & 4.8 & 6.1 & 6.3 & 0.25 & 0.21 & 0.16 & 29.6 & 35.7 & 40.2 \\
\hline $\mathbf{B S P}_{5}$ & 4.9 & 5.7 & 5.9 & 0.61 & 0.43 & 0.41 & 36.5 & 40.7 & 46.8 \\
\hline BSP $_{6}$ & 6.2 & 7.0 & 7.3 & 0.31 & 0.30 & 0.25 & 26.8 & 34.4 & 40.2 \\
\hline $\mathrm{BSP}_{7}$ & 6.8 & 7.4 & 7.5 & 0.97 & 0.69 & 0.56 & 32.1 & 32.5 & 39.1 \\
\hline $\mathrm{BSP}_{8}$ & 5.9 & 6.4 & 6.6 & 1.49 & 1.14 & 1.09 & 38.2 & 40.3 & 42.8 \\
\hline $\mathrm{BSP}_{9}$ & 6.1 & 7.2 & 7.4 & 0.32 & 0.15 & 0.09 & 33.5 & 39.4 & 39.2 \\
\hline $\mathbf{B S P}_{10}$ & 6.2 & 6.6 & 6.9 & 0.32 & 0.22 & 0.09 & 37.0 & 40.3 & 40.1 \\
\hline $\mathrm{BSP}_{23}$ & 7.1 & 7.4 & 7.7 & 13.64 & 13.00 & 12.46 & 44.0 & 46.2 & 48.1 \\
\hline Sree Bhadra & 5.8 & 6.1 & 6.6 & 2.95 & 2.61 & 2.40 & 32.1 & 34.1 & 37.9 \\
\hline Mean & 5.8 & 6.6 & 6.8 & 2.05 & 1.81 & 1.67 & 34.4 & 38.1 & 41.6 \\
\hline S.Em \pm & 0.11 & 0.09 & 0.12 & 0.03 & 0.04 & 0.05 & 0.40 & 0.33 & 0.17 \\
\hline C.D. @ 1\% & 0.42 & 0.35 & 0.47 & 0.11 & 0.14 & 0.20 & 1.57 & 1.30 & 0.69 \\
\hline
\end{tabular}

DAS: days after storage 
Table.2 Performance of sweet potato genotypes in retaining reducing sugars (\%), non-reducing sugars (\%) and starch content (\%)

\begin{tabular}{|c|c|c|c|c|c|c|c|c|c|}
\hline \multirow[t]{3}{*}{ Genotypes } & \multicolumn{3}{|c|}{ Reducing sugars (\%) } & \multicolumn{3}{|c|}{ Non-reducing sugars (\%) } & \multicolumn{3}{|c|}{ Starch $(\%)$} \\
\hline & \multicolumn{9}{|c|}{ DAS } \\
\hline & $\mathbf{0}$ & 15 & 30 & $\mathbf{0}$ & 15 & 30 & $\mathbf{0}$ & 15 & 30 \\
\hline $\mathbf{B S P}_{1}$ & 0.67 & 0.55 & 0.35 & 0.21 & 0.42 & 0.59 & 0.60 & 0.50 & 0.32 \\
\hline $\mathbf{B S P}_{2}$ & 0.80 & 0.76 & 0.72 & 0.25 & 0.29 & 0.35 & 0.72 & 0.69 & 0.65 \\
\hline $\mathrm{BSP}_{3}$ & 0.91 & 0.86 & 0.70 & 0.18 & 0.24 & 0.40 & 0.82 & 0.78 & 0.63 \\
\hline $\mathbf{B S P}_{4}$ & 0.68 & 0.64 & 0.48 & 0.13 & 0.21 & 0.47 & 0.61 & 0.57 & 0.43 \\
\hline $\mathbf{B S P}_{5}$ & 0.72 & 0.60 & 0.54 & 0.10 & 0.25 & 0.34 & 0.64 & 0.54 & 0.49 \\
\hline $\mathbf{B S P}_{6}$ & 0.61 & 0.57 & 0.51 & 0.11 & 0.22 & 0.34 & 0.55 & 0.51 & 0.46 \\
\hline $\mathbf{B S P}_{7}$ & 0.61 & 0.51 & 0.46 & 0.08 & 0.21 & 0.32 & 0.55 & 0.46 & 0.41 \\
\hline BSP $_{8}$ & 0.60 & 0.54 & 0.52 & 0.22 & 0.34 & 0.40 & 0.54 & 0.49 & 0.47 \\
\hline BSP9 & 0.69 & 0.65 & 0.63 & 0.17 & 0.23 & 0.29 & 0.62 & 0.59 & 0.56 \\
\hline $\mathbf{B S P}_{10}$ & 0.63 & 0.62 & 0.54 & 0.19 & 0.28 & 0.39 & 0.57 & 0.55 & 0.49 \\
\hline $\mathrm{BSP}_{23}$ & 1.44 & 1.37 & 1.19 & 0.13 & 0.23 & 0.42 & 1.30 & 1.23 & 1.07 \\
\hline $\begin{array}{c}\text { Sree } \\
\text { Bhadra }\end{array}$ & 0.68 & 0.65 & 0.62 & 0.29 & 0.35 & 0.42 & 0.61 & 0.59 & 0.55 \\
\hline Mean & 0.75 & 0.69 & 0.60 & 0.17 & 0.27 & 0.39 & 0.68 & 0.62 & 0.54 \\
\hline S.Em \pm & 0.01 & 0.01 & 0.03 & 0.03 & 0.02 & 0.04 & 0.01 & 0.01 & 0.03 \\
\hline C.D. @1\% & 0.04 & 0.05 & 0.13 & 0.10 & 0.07 & 0.14 & 0.05 & 0.04 & 0.11 \\
\hline
\end{tabular}

DAS: Days after storage

Table.3 Performance of sweet potato genotypes in retaining ascorbic acid content $(\mathrm{mg} / 100 \mathrm{~g})$, total titratable acidity (\%) and physiological loss in weight (\%)

\begin{tabular}{|c|c|c|c|c|c|c|c|c|}
\hline \multirow[t]{3}{*}{ Genotypes } & \multicolumn{3}{|c|}{ Ascorbic acid (mg/100g) } & \multicolumn{3}{|c|}{ Total titratable acidity (\%) } & \multicolumn{2}{|c|}{ Physiological loss in weight (\%) } \\
\hline & \multicolumn{8}{|c|}{ DAS } \\
\hline & $\mathbf{0}$ & 15 & 30 & $\mathbf{0}$ & 15 & 30 & 15 & 30 \\
\hline $\mathrm{BSP}_{1}$ & 16.30 & 10.87 & 5.43 & 0.19 & 0.27 & 0.15 & 13.5 & 22.9 \\
\hline $\mathrm{BSP}_{2}$ & 14.49 & 10.87 & 5.43 & 0.31 & 0.35 & 0.27 & 15.1 & 31.9 \\
\hline $\mathrm{BSP}_{3}$ & 21.74 & 16.30 & 10.87 & 0.27 & 0.35 & 0.19 & 12.4 & 28.5 \\
\hline $\mathrm{BSP}_{4}$ & 25.36 & 19.93 & 12.68 & 0.31 & 0.39 & 0.27 & 30.3 & 42.3 \\
\hline $\mathrm{BSP}_{5}$ & 23.55 & 18.12 & 12.68 & 0.27 & 0.31 & 0.23 & 13.4 & 31.5 \\
\hline BSP $_{6}$ & 12.68 & 10.87 & 5.43 & 0.31 & 0.31 & 0.27 & 15.7 & 37.7 \\
\hline $\mathrm{BSP}_{7}$ & 14.49 & 9.06 & 5.43 & 0.23 & 0.31 & 0.19 & 17.8 & 35.0 \\
\hline $\mathrm{BSP}_{8}$ & 21.74 & 14.49 & 5.43 & 0.31 & 0.35 & 0.23 & 15.0 & 31.4 \\
\hline $\mathrm{BSP}_{9}$ & 18.12 & 9.06 & 5.43 & 0.35 & 0.39 & 0.23 & 14.0 & 35.7 \\
\hline BSP $_{10}$ & 18.12 & 12.68 & 7.25 & 0.31 & 0.31 & 0.23 & 11.4 & 31.1 \\
\hline $\mathrm{BSP}_{23}$ & 21.74 & 14.49 & 9.06 & 0.39 & 0.46 & 0.31 & 10.9 & 23.6 \\
\hline Sree Bhadra & 18.12 & 12.68 & 7.25 & 0.35 & 0.39 & 0.31 & 14.6 & 28.5 \\
\hline Mean & 18.87 & 13.28 & 7.70 & 0.30 & 0.35 & 0.24 & 15.3 & 31.7 \\
\hline S.Em \pm & 1.73 & 1.48 & 1.17 & 0.06 & 0.06 & 0.05 & 0.88 & 1.10 \\
\hline C.D. @1\% & 6.86 & 5.85 & 4.63 & NS & NS & NS & 3.48 & 4.34 \\
\hline
\end{tabular}

DAS: Days after storage 
Ascorbic acid (mg/100g) and total titratable acidity $(\%)$

The genotypes differ in the amount of ascorbic acid content as stated by Singh $e t$ al., (2005) and it decrease on storage in ambient condition. However in the present investigation, the ascorbic acid content in the tubers decreased in all the genotypes as the storage time progressed. The maximum amount of ascorbic acid was recorded in $\mathrm{BSP}_{4}$ on initial and 15 DAS respectively (25.36 and $19.93 \mathrm{mg} / 100 \mathrm{~g}$ ). Further on $30 \mathrm{DAS}$, two genotypes $\mathrm{BSP}_{4}$ and $\mathrm{BSP}_{5}$ recorded maximum amount of ascorbic acid $(12.68 \mathrm{mg} / 100 \mathrm{~g}$ each). A significant decrease in ascorbic acid noticed, could be due to enzymatic loss of Lascorbic acid where it is converted to 2-3dioxy-L-gluconic acid (Mapson, 1970). These results were found to be in line with the investigations of Cruz-rus et al., (2011) in strawberry and Brar et al., (2013) in potato. The total titratable was found to vary nonsignificantly (Table 3 ).

\section{Physiological loss in weight (\%)}

The PLW increases with progress in storage period however the values of PLW are a genotype dependent factor (Amoah et al., 2011). In the present study, minimum PLW $(10.9 \%)$ was recorded in $\mathrm{BSP}_{23}$ on $15^{\text {th }}$ day while on $30^{\text {th }}$ day, minimum PLW among all genotypes was recorded in $\mathrm{BSP}_{1}(22.9 \%)$. This difference in PLW might be due to the difference in respiration and transpiration rates in different genotypes and also increase in respiration rate as the storage prolonged (Mehta and Singh, 2002). These reports were found to be in line with the study by Huang $e t$ al., (2014) in sweet potato.

As evident from the overall assessment on the results obtained, the genotype $\mathrm{BSP}_{1}$ was found to perform best among all the genotypes in ambient storage condition with its desirable characters like low TSS, low amount of reducing sugars, low PLW, low moisture content, high dry matterand so on. It was also able to retain its qualities throughout the storage period.

\section{References}

Abdullah, B. Y. and Safraiy, S. A. A. 2015, Study of chemical and physical characteristics for some potato cultivars available locally and evaluation of chips produced from them. Fd. Sci.4 (15): 157-166.

Agbemafle, R., Sekyere, O. J. D., Otchere, J. K., Acquaye, A., Diabor, E., Asi, J., 2014, Effect of different storage methods on the proximate composition and functional properties of cream-skinned sweet potato (Ipomoea batatas L.). Sch. J. Eng. Tech., 2 (1): 33-44.

Amoah, R. S., Teye, E., Abano, E. E., Tetteh, J. P., 2011, The storage performance of sweet potatoes with different pre-storage treatments in an evaporative cooling barn. Asian J. Agric. Res., 5 (2): 137-145.

AOAC, 1990, Official Methods of Analysis (Vol. 2), Washington D.C., Association of Official Analytical Chemist.

Bates, F. L., French, D. and Rundle, R. E., 1943, Amylose and amylopectin content of starches determined by their iodine complex formation. J. Am. Chem. Soc., 65 (2): 142-148.

Blessington, T., Nzaramba, M. N., Scheuring, D. C., Hale, A. L., Reddivari, L., and Miller, J. C., 2010, Cooking methods and storage treatments of sweet potato: Effects on carotenoids, antioxidant activity, and phenolics. Am. J. Res., 87: 479-491.

Brar, A, 2013, Storage studies in potato (Solanum tuberosum) under ambient condition. $M$. Sc. Thesis, Chaudhary Charan Singh Haryana Agril. Uni. Hissar (India).

Cruz-rus, E., Amaya, I., Sevilla, S., Botella, M. and Valpuesta, V., 2011, Regulation of Lascorbic acid content in strawberry fruits. J. Exp. Bot., 62(12): 4191-4201.

Desai, K. D., Saravaiya, S. N., Patel, N. B., Padhiar, B. V., More, S. J. and Tekale, G. S., 2013, Evaluation of orange-fleshed 
sweet potato genotypes (Ipomoea batatas L.) under south Gujarat conditions. $J$. Root Crops, 39(2): 232-233.

Ellong, E. N., Billard, C. and Adenet., S, 2014, Comparison of physicochemical, organoleptic and nutritional abilities of eight sweet potato varieties. Fd. Nutri. Sci., 5: 196-211.

Emmanuel, H., Vasanthalkaalam, H., Ndirigwe, J. and Mukwantali, C., 2010, A comparative study on the beta-carotene content and its retention on yellow and orange fleshed sweet potato flours. www.asareca.org.

Ezekiel, R., and Rani, M., 2006, Oil content of potato chips: Relationship with dry matter and starch content and rancidity during storage at room temperature. Potato Journal, 33: 1-2.

Huang, C. L., Wayne C. L., Chin, F. C. and Yung, C.L., 2014, Storage performance of Taiwanese sweet potato cultivars. $J$. Fd. Sci., 51(12): 4019-4025.

Ingabire, M.R. and Hilda, V., 2011, Comparison of the nutrient composition of four sweet potato varieties cultivated in Rwanda. Am. J. Fd. and Nutri., 1(1): 34-38.

Khayatnezhad, M., Shahriari, R., Gholamin, R., Jamaati-e-Somarin, S. and Zabihi-eMahmoodabad, R., 2011, Correlation and path analysis between yield and yield components in potato (Solanum tubersum L.). Middle-East J. Scientific Res., 7(1): 17-21.

Kumar, D., Singh, J., Singh, S. V., 2002, Changes in the sugars and dry matter content in tubers of some Indian potato cultivars and exotic hybrids stored at high temperature. Potato, Global Research and Development, 2: 1096-1100.

Maldegem, J. P. V., 1999, State of the art techniques for the sweet potato storage. Abstract, Global Conference on Sweet Potato, New Delhi, 6-11.

Mapson, L. W., 1970, In: The Biochemistry of Fruits and Their Products (Ed. Hulme, A.C.). Academic Press, London, UK, 1: 369-384.

Mehta, A. and Singh, S. P., 2002, Physiological losses in potatoes under non-refrigerated storage: effect of N, P and K fertilizers. $J$. the Indian Potato Association, 29(3-4): 129-134.

Miller, G. L., 1972, Use of Dinitro-Salicylic acid reagent for determination of reducing sugars. Annual Chem., 31: 426-428.

Pressey, R. and Shaw, R., 1996, Effect of temperature on invertase: invertase inhibitor and sugars in sweet potato tubers. Plant Physiology, 41: 1657-1661.

Serge, T. and Tom, A. E., 1996, Biochemical changes occurring during growth and storage of two yam species. Int. J. Fd. Sci. and Nutri.,47: 93-102.

Shekhar, S., Mishra, D., Buragohain, A. K., Chakraborty, S., Chakraborty, N., 2015, Comparative analysis of phytochemicals and nutrient availability in two contrasting cultivars of sweet potato (Ipomoea batatas L). Fd. Chem., 173:957-965.

Singh, R. K., Marwaha, R. S., Sharma, J. and Singh, S., 2005, Antioxidant status and tuber yield in different potato cultivars. Potato Journal, 32(3): 199-200.

Zhang, Z., Christopher, C. W. and Harold, C., 2002, Biochemical changes during storage of sweet potato roots differing in dry matter content. Post harvest Bio. and Technol., 24: 317-325.

\section{How to cite this article:}

Prathiksha and Ramachandra Naik, K. 2019. Efficiency of Sweet Potato (Ipomoea batatas L.) Genotypes in Retention of Processing Qualities under Ambient Conditions. Int.J.Curr.Microbiol.App.Sci. 8(06): 2609-2615. doi: https://doi.org/10.20546/ijcmas.2019.806.313 